http://dx.doi.org/10.1590/1678-4162-9575

Arq. Bras. Med. Vet. Zootec., v.69, n.6, p.1676-1682, 2017

\title{
Microbiota bacteriana de ovos de jacaré-do-pantanal incubados naturalmente
}

\author{
[Bacterial microbiota of the Pantanal caiman eggs incubated in nature] \\ R. Pulcherio ${ }^{1}$, F.H. Maruyama ${ }^{1}$, T. Dorado-Rodrigues ${ }^{2}$, M. Silveira ${ }^{1}$, V. Dutra ${ }^{1}$, R. Ferraz ${ }^{1}$ \\ ${ }^{1}$ Programa de pós-graduação - Faculdade de Medicina Veterinária - Universidade Federal \\ de Mato Grosso - Cuiabá, MT \\ ${ }^{2}$ Programa de pós-graduação - Instituto de Biociências - Universidade Federal de Mato Grosso - Cuiabá, MT
}

\begin{abstract}
RESUMO
A cadeia produtiva do Caiman yacare tem-se destacado no Mato Grosso com a exportação de 143.386 peles em 2015, cujo sistema de manejo (ranching) implica a incubação artificial dos ovos. Nesse processo, a contaminação bacteriana de ovos influencia a taxa de eclosão. O conhecimento da microbiota de ovos incubados naturalmente orienta o manejo sanitário adequado no incubatório. No presente estudo, são apresentadas informações sobre essa microbiota e sua correlação com a de outros crocodilianos, apontando-se as espécies com potencial patogênico. Amostras de 20 ninhos de C. yacare foram coletadas e semeadas em ágar sangue e ágar Mac Conckey. A colônia condizente com Salmonella sp. foi confirmada pela técnica de reação em cadeia de polimerase. Das 22 espécies bacterianas isoladas, 59\% pertencem à família Enterobacteriaceae e $41 \%$ a outros táxons bacterianos. A semelhança dos achados com as bactérias isoladas na microbiota oral e/ou intestinal/cloacal de crocodilianos foi de $77,27 \%$. As bactérias mais e menos frequentes foram, respectivamente, Bacillus cereus, Flavobacterium multivorum, Citrobacter freundii, Escherichia hermannii, Hafnia alvei, Morganella, morganni, Salmonella sp., Serratia marcescens e Shigella sonnei. Das bactérias isoladas, 86,36\% têm potencial patogênico para crocodilianos. A origem materna e a ambiental da microbiota de ovos incubados naturalmente são, respectivamente, de $77,27 \%$ e $27,27 \%$.
\end{abstract}

Palavras-chave: ranching, criação comercial, enterobactéria, microbiota, ninho

\begin{abstract}
The Pantanal caiman productive chain has grown in Mato Grosso with the exportation of 143.383 leather pieces in 2015, whose management system (ranching) implies the artificial incubation of eggs. In this process, the bacterial contamination of the eggs influences the hatching rate. Knowledge of the naturally incubated microbiota of eggs guides the appropriate sanitary management in the incubator room. Here we present information about this microbiota and correlate it with that of other crocodilians, indicating the species with pathogenic potential. Samples were collected in 20 nests at Pantanal, and sown in blood and Mac Conckey agar. Salmonella sp. was confirmed through polymerase chain reaction technique. From the twenty-two different species of bacteria isolated, 59\% are from the Enterobacteriaceae Family and $41 \%$ from other bacterial taxonomies. The similarity of findings to isolated bacteria in the crocodilians oral and/or intestinal/cloacal microbiota was of 77,27\%. The most and least frequent bacteria were, respectively, Bacillus cereus, Flavobacterium multivorum and Citrobacter freundii and Escherichia hermannii, Hafnia alvei, Morganella, morganni, Salmonella sp., Serratia marcescens and Shigella sonnei. Among the isolated bacteria, 86,36\% are pathogenic for crocodilians. The maternal and environmental origin of the microbiota of eggs naturally incubated is, respectively, of 77,27\% and $27,27 \%$.
\end{abstract}

Keywords: ranching, commercial breeding, enterobacteria, microbiota, nest

Recebido em 9 de novembro de 2016

Aceito em 19 de janeiro de 2017

E-mail: rachel.sousa@svc.ifmt.edu.br 


\section{INTRODUÇÃO}

Caiman yacare Daudin, 1802 (jacaré-dopantanal) é uma das seis espécies de crocodilianos que ocorrem no Brasil (Costa e Bérnils, 2014), cuja cadeia produtiva tem alcançado grande destaque econômico no estado do Mato Grosso (Oliveira et al., 2015) com a exportação de 143.386 mil peles em 2015 (Brasil, 2015b). No Brasil, o sistema de manejo de crocodilianos, denominado ranching, é um dos sistemas autorizados pelos órgãos ambientais competentes, sendo o mais implementado, e consiste na coleta de ovos ou filhotes na natureza, na incubação artificial dos ovos e na recria dos jovens (Brasil, 2015a).

Apesar de a presença de bactérias em ninhos de crocodilianos facilitar a eclosão dos ovos durante o final do processo de incubação, devido à ação de ácidos resultantes do metabolismo bacteriano sobre a camada externa do ovo (Ferguson, 1981), na incubação artificial, o manuseio inadequado dos ovos no momento da coleta pode levar à contaminação por bactérias e fungos (Bassetti e Verdade, 2014). Em ovos com irregularidade na formação da casca calcária (Fernández et al., 2013), a contaminação durante esse processo é considerada a principal causa de morte embrionária. As bactérias isoladas da casca de ovos de crocodilianos de cativeiro ou em ovos não eclodidos, cujo conteúdo estava contaminado (Peuker et al., 2005), também foram descritas na microbiota cloacal de crocodilianos (Huchzermeyer et al., 2000; Lovely e Leslie, 2008; Silva et al., 2009; Johnston et al., 2010). Essa microbiota cloacal pode estar ligada a microrganismos presentes no sistema digestório (Ferreira Júnior et al., 2009; White et al., 2011; Benites et al., 2013; Chiacchio et al., 2014) e, assim como a microbiota ambiental, pode não só comprometer o desenvolvimento do ovo, mas também desencadear alterações clínicas em crocodilianos (Huchzermeyer, 2003; Paré et al., 2006; Yoon-Seok et al., 2011; Oliveira et al., 2015).

Pouco se sabe a respeito do mecanismo pelo qual as bactérias agem, bem como sobre a composição dessa microbiota em ovos de crocodilianos, tanto em condições de incubação natural quanto artificial. Assim, para a realização de adequado manejo reprodutivo em cativeiro, são necessárias informações prévias sobre a microbiota de ovos em condições de incubação natural. A implementação de adequado manejo sanitário durante a incubação artificial minimiza a contaminação dos ovos por bactérias, sobretudo pelas potencialmente patogênicas, as quais comprometem o desenvolvimento embrionário.

No presente estudo, foi realizada a caracterização da microbiota de ovos de Caiman yacare registrada no momento da coleta, previamente à incubação artificial, com o objetivo de inferir a origem dessa microbiota. Além disso, a microbiota registrada foi correlacionada com a microbiota de outros crocodilianos e/ou outros répteis, a fim de sinalizarem-se as espécies bacterianas com algum potencial patogênico.

\section{MATERIAL E MÉTODOS}

O estudo foi realizado em uma área do Pantanal Norte, localizada no município de Poconé, em abril de 2011 (conforme aprovação pelo Comitê de Ética em Pesquisa Animal; Cepa/UFMT, protocolo 23108.044293/10-8). A propriedade realiza a coleta e a incubação artificial de ovos destinados à criação comercial, sendo coletados aleatoriamente neste estudo 20 ninhos. Após a abertura dos ninhos, as amostras microbiológicas foram obtidas da superfície exposta dos ovos por meio de suabe. Foram acondicionadas em meio de transporte (meio de Stuart), resfriadas a aproximadamente $4^{\circ} \mathrm{C}$ em recipiente isotérmico e transportadas para o processamento, não excedendo o período de 24 horas até a semeadura (Quinn et al., 2001).

O material coletado foi semeado em ágar sangue e ágar Mac Conckey para a identificação de bactérias, sendo incubado em ambiente aeróbico e anaeróbico a $37^{\circ} \mathrm{C}$ e observado a cada $24 \mathrm{~h}$, por até 72 horas. Após a observação do crescimento bacteriano, as colônias foram identificadas de acordo com suas características morfotintoriais e provas bioquímicas (Quinn et al., 2001). A colônia condizente com Salmonella sp. foi confirmada por meio da técnica de reação em cadeia de polimerase (PCR), sendo a extração realizada segundo a técnica de fervuracentrifugação descrita por Soumet et al. (1994) e a PCR conforme Suh e Song (2005), utilizandose um par de primers que originam produtos de amplificação de $298 \mathrm{pb}$ correspondente ao gene invA. 
A frequência das bactérias isoladas foi calculada de forma percentual, de acordo com o número total de ninhos coletados. A ocorrência de uma espécie em um ninho correspondeu a $5 \%$.

\section{RESULTADOS}

Todas as amostras de ovos de Caiman yacare oriundas dos 20 ninhos naturalmente incubados obtiveram crescimento bacteriano. Foram isoladas 22 diferentes espécies, sendo quatro delas identificadas em nível de gênero (Salmonella sp., Acinetobacter sp., Alcaligenes sp. e Streptococcus sp.). As espécies que apresentaram maior frequência foram Bacillus cereus (95\%), Flavobacterium multivorum (80\%) e Citrobacter freundii (75\%), sendo a mínima de 5\% para as demais espécies (Fig. 1).

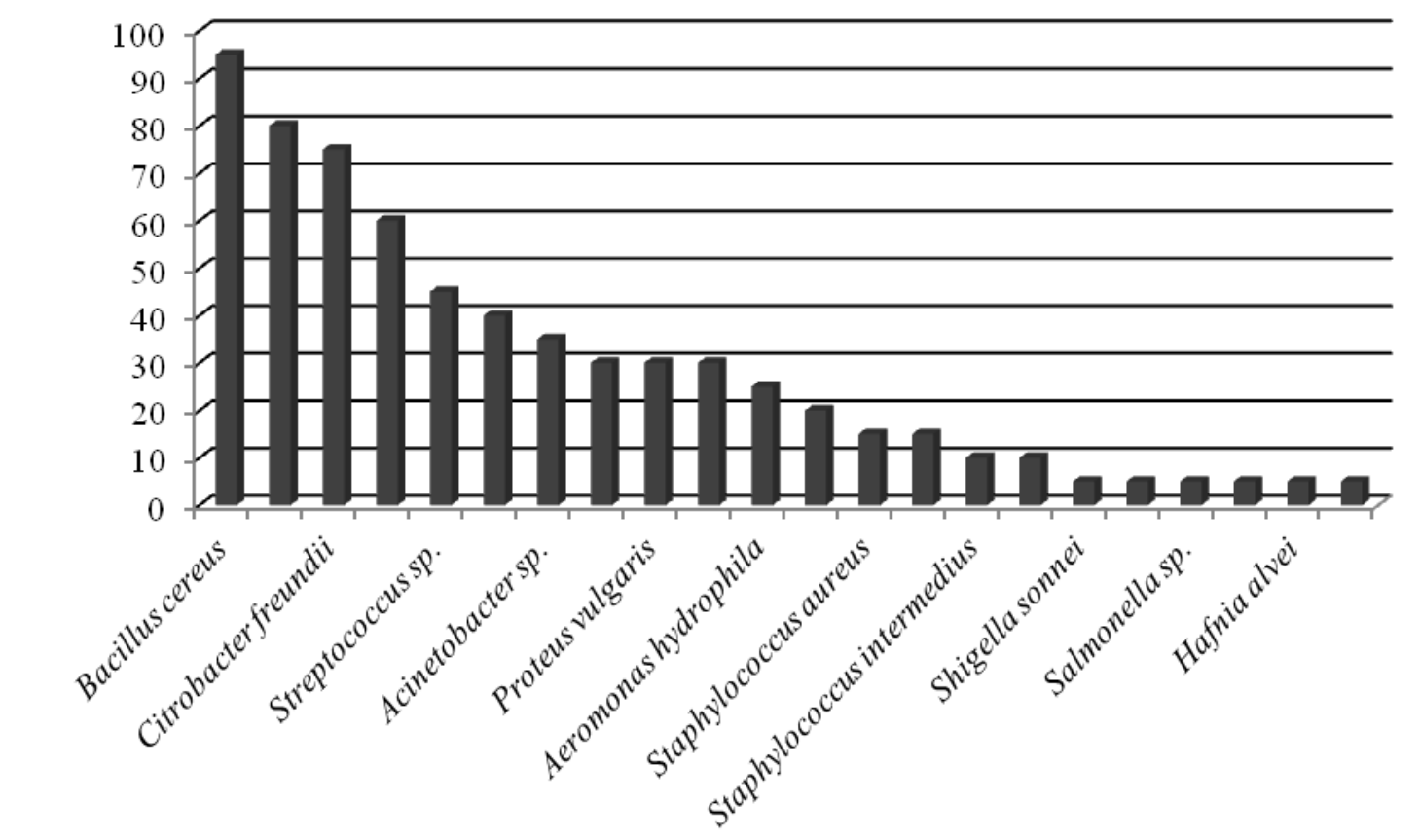

Figura 1. Percentual de ocorrência de bactérias com frequência maior ou igual a 5\% nos 20 ninhos de Caiman yacare, Poconé, 2011.

Em relação à classificação bacteriana, 59\% pertencem à família Enterobacteriaceae (Citrobacter freundii, Enterobacter aerogenes, Enterobacter agglomerans, Escherichia coli, Escherichia hermannii, Hafnia alvei, Morganella morganni, Proteus vulgaris, P. mirabilis, Salmonella sp., Serratia liquefaciens, $S$. marcescens e Shigella sonnei), $13,6 \%$ são cocos Gram positivos (Streptococcus sp., Staphylococcus aureus e Staphylococcus intermedius), 4,6\% são bacilo Gram positivo (Bacillus cereus,) e bacilo Gram negativo (Aeromonas hydrophila) cada um e $2 \%$ se classificam como bactérias Gram negativas não fermentadoras da glicose (Acinetobacter sp., Alcaligenes sp., Flavobacterium multivorum e Pseudomonas stutzeri).
A diversidade bacteriana observada em ovos de Caiman yacare em comparação a outros crocodilianos é apresentada na Tab. 1.

\section{DISCUSSÃO}

A microbiota bacteriana encontrada nos ovos de Caiman yacare foi bastante diversificada, em virtude de sua dupla origem: organismo materno e meio ambiente. Esse padrão de diversidade bacteriana é semelhante ao registrado na microbiota cloacal de répteis, descrito na literatura de forma genérica (Zancolli et al., 2015) ou de acordo com táxon específico, como em cascavéis (Ferreira Júnior et al., 2009); lagartos comuns (White et al., 2011); jabutispiranga (Benites et al., 2013) e tartarugas-doouvido-vermelho (Chiacchio et al., 2014). 
Tabela 1. Espécies bacterianas identificadas por meio de suabe da superfície de ovos de Caiman yacare incubados naturalmente $(\mathrm{OCy})$ comparadas às isoladas de diferentes regiões $(\mathrm{O}=$ oral; $\mathrm{CS}=$ casca do ovo; $\mathrm{CO}$ = conteúdo do ovo; $\mathrm{I}$ = intestino ou conteúdo intestinal; $\mathrm{CL}$ = cloaca) em diversas espécies de crocodilianos de vida livre* e cativeiro**

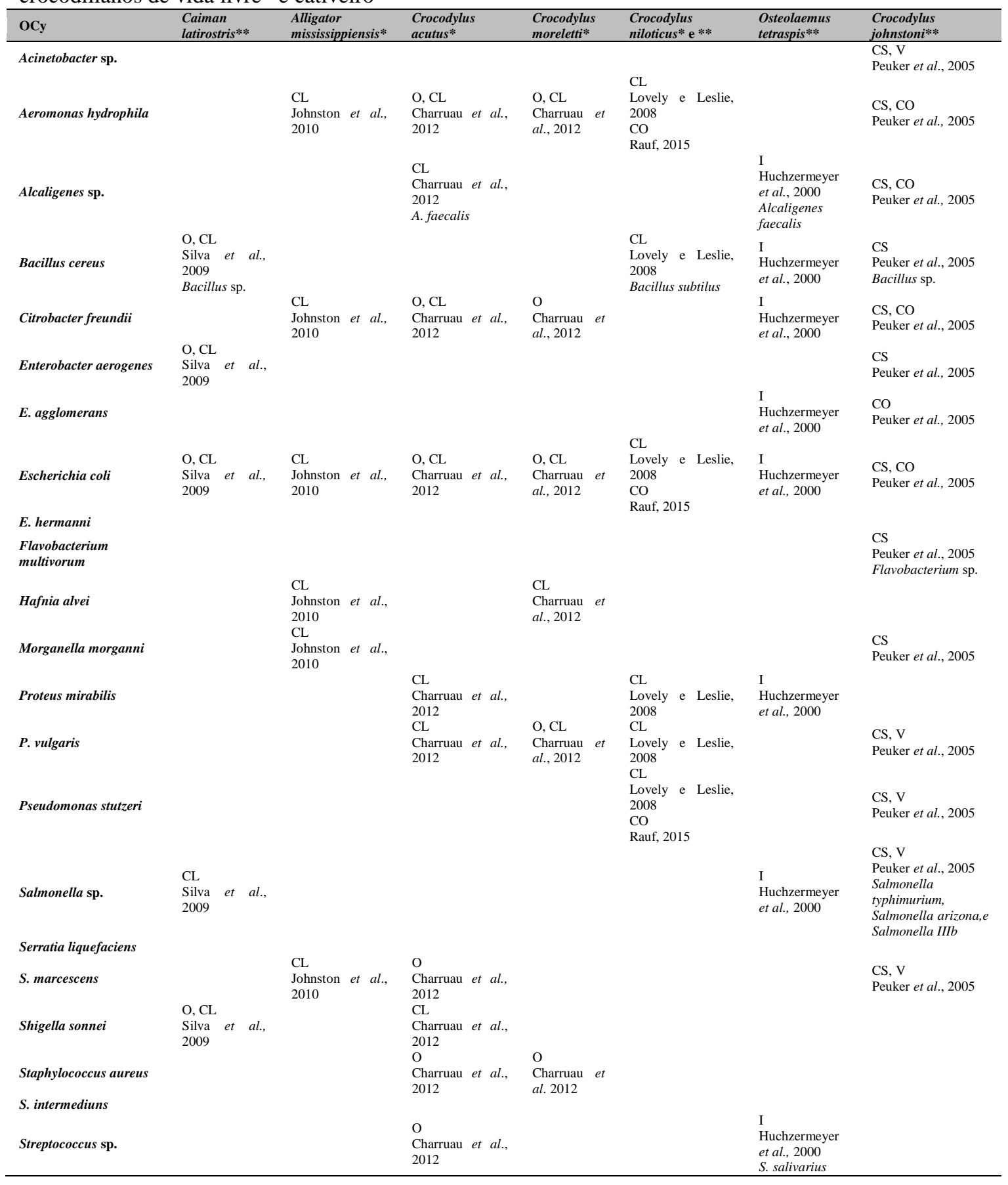

Entre as bactérias isoladas da superfície de ovos de C. yacare, $17 / 22 \quad(77,27 \%)$ já foram identificadas (Tab. 1) como integrantes da microbiota intestinal/cloacal e/ou oral de crocodilianos (Huchzermeyer et al., 2000; Lovely e Leslie, 2008; Johnston et al., 2010; Silva et al., 2009; Charruau et al., 2012). A maior ocorrência de espécies da família 
Enterobacteriaceae pode justificar a similaridade marcante entre crocodilianos de diferentes regiões, cuja composição da microbiota intestinal desse grupo possivelmente seja decorrente do tipo de presa ingerida (Ferreira Júnior et al., 2009), o que levanta a hipótese de que a similaridade da microbiota possa estar relacionada à evolução de crocodilianos.

A semelhança entre a microbiota intestinal e a do ovo pode ser explicada, por um lado, pelas relações anatômicas, em que segmentos distais do intestino grosso e oviduto desembocam na cloaca, criando a condição física para as bactérias distribuírem-se pela superfície do ovo (Bassetti e Verdade, 2014). Por outro lado, a mãe defeca no ninho durante a oviposição, transferindo para esse ambiente os microrganismos presentes nas fezes (Huchzermeyer, 2003). Além disso, a dependência materna de substrato para a confecção do ninho, oriundo do ambiente em que ela esteja, torna a microbiota do substrato potencialmente presente na superfície do ovo.

A transferência de microbiota entérica, seja pela transferência dela para o ovo ao passar pelo proctodeu, seja pela defecação da mãe durante a oviposição (Huchzermeyer, 2003), ou quando proveniente da matéria orgânica utilizada pela fêmea para a construção do ninho, deve ser considerada, respectivamente, transferência vertical e transferência horizontal (Singh et al., 2014), como já caracterizado para aves e outras espécies animais (Funkhouser e Bordenstein, 2013). Segundo esses autores, a transferência materna (vertical) de microrganismos à progênie parece ser um fenômeno universal no reino animal, como já sinalizado por Singh et al. (2014), que atribuem a origem materna e não ambiental para a maior parte da microbiota de ovos de geckos (Hemidactylus frenatus). Assim como em outros répteis, a provável via são os órgãos genitais da fêmea durante a oviposição, embora esse mecanismo ainda não tenha sido demonstrado. No entanto, considerando a similaridade entre as espécies bacterianas isoladas de ovos de C. yacare e as já relatadas na cloaca de outros crocodilianos, é possível afirmar que a origem dessa microbiota seja materna.

As espécies Flavobacterium multivorum e Escherichia hermannii, embora tenham sido isoladas, respectivamente, na microbiota das glândulas gular e paracloacal de Alligator mississippiensis (Williams et al., 1990), também foram isoladas em ovos de $C$. yacare. Está evidente que há transferência dessa microbiota glandular, durante os cuidados da mãe na construção e no fechamento do ninho (gular), bem como eliminação de material glandular (cloacal) juntamente com a oviposição, levando a se questionar se a colonização da glândula paracloacal pela Escherichia hermannii não seja secundária à da microbiota intestinal.

Das bactérias que não pertencem à família Enterobacteriacea $(41 \%)$, a espécie Bacillus cereus, amplamente encontrada no ar, no solo e na água (Quinn et al., 2001), foi a mais frequente (95\%) em ovos incubados naturalmente de $C$. yacare, mas a menos frequente, isolada do sistema digestório de Osteolaemus tetraspis aparentemente sadios (Huchzermeyer et al., 2000).

Das bactérias isoladas, $86,36 \%$ já foram descritas como patogênicas para crocodilianos (Schoeb et al., 2002; Paré et al., 2006; Gairhe, 2007; Quinn et al., 2001; Yoon-Seok et al., 2011), incluindo o comportamento oportunista de contaminação de ovos (Peuker et al., 2005; Rauf, 2015), e 27,27\% são comumente isoladas de amostras ambientais, como água, solo e vegetação (Quinn et al., 2001).

Muitos relatos atribuem o potencial patogênico às espécies bacterianas já isoladas da cloaca e até mesmo àquelas de origem ambiental. Huchzermeyer (2003) afirma que a microbiota da cloaca pode ser responsável por infecções no ovo durante a postura, por atravessar os poros da casca e estabelecer-se em seu conteúdo, no entanto Bassetti e Verdade (2014) afirmam serem necessárias condições desfavoráveis (manuseio inadequado e temperatura e umidade altas) para haver a infecção do ovo por bactérias e fungos. Peuker et al. (2005) relatam ainda ser possível a contaminação dos ovos no oviduto da fêmea, antes da postura, o que poderia ser considerado como transmissão vertical, à semelhança do que ocorre em aves, cuja origem materna também é ressaltada por Funkhouser e Bordenstein (2013) e Singh et al. (2014); ou ainda, segundo Rauf (2015), a contaminação pode ocorrer por microrganismos do ambiente, seja em incubação natural (material do ninho), 
seja em artificial (vermiculita ou incubadora), caracterizando a transmissão horizontal.

Aeromonas hydrophila, Citrobacter freundii, Enterobacter agglomerans, Hafnia alvei, Morganella morganni, Serratia liquefaciens, Serratia marcescens, Staphylococcus aureus e Streptococcus sp. já foram isoladas do sangue de Alligator mississippiensis doentes (Novak e Seigel, 1986; Schoeb et al., 2002), de Crocodylus johnstoni e Crocodylus porosus com septicemia (Yoon-Seok et al., 2011), bem como do sangue e dos órgãos de filhotes de Gavialis gangeticus (Gairhe, 2007). Os mecanismos dessa patogenia, em especial, na descrição de como essa microbiota se torna patogênica, seja para o embrião seja para o animal eclodido (jovem ou adulto), são pouco explorados, no entanto fatores como temperatura e umidade altas (Ferguson, 1981), manuseio inadequado dos ovos (Bassetti e Verdade, 2014) ou ovos irregularmente calcificados (Fernández et al., 2013) constituemse condições predisponentes que oferecem risco, particularmente, de contaminação para os ovos.

\section{CONCLUSÕES}

O crescimento bacteriano ocorreu em $100 \%$ dos ninhos de Caiman yacare, em cuja superfície dos ovos foram identificadas 22 diferentes espécies de bactérias, sendo $59 \%$ pertencentes à família Enterobacteriaceae e $41 \%$ pertencentes a outros diversos táxons bacterianos. A microbiota da superfície de ovos de Caiman yacare incubados naturalmente foi semelhante $(77,27 \%)$ à de outras espécies de crocodilianos, de diferentes localidades, cuja origem, descrita por meio da microbiota oral e/ou cloacal/intestinal, caracteriza a transferência vertical (origem materna). Quanto às bactérias identificadas como de origem ambiental, a transferência horizontal foi de 27,27\%. Das espécies bacterianas identificadas na superfície de ovos de Caiman yacare, $86,36 \%$ já foram descritas como potencialmente patogênicas para crocodilianos.

\section{AGRADECIMENTOS}

À Fazenda Ypiranga e à Pousada Piuval, nas pessoas dos senhores João Losano Eubank de Campos e Eduardo Matos Eubank de Campos, por viabilizarem a realização deste experimento.

\section{REFERÊNCIAS}

BASSETTI, L.A.B.; VERDADE, L.M. Crocodylia (jacarés e crocodilos). In: CUBAS, Z.S.; SILVA, J.C.R.; CATÃO-DIAS, J.L. (Eds.). Tratado de animais selvagens: medicina veterinária. 2.ed. São Paulo: Roca, 2014. cap.13, p.154-169.

BENITES, N.R.; PESSOA, C.; BANDINI, L. et al. Microbiota bacteriana e fúngica presentes na cloaca de jabutis-piranga (Geochelone carbonaria) criados em domicílio. Vet. Zootec., v.20, p.102-110, 2013.

BRASIL. Instituto Brasileiro do Meio Ambiente e dos Recursos Naturais Renováveis. Instrução Normativa $n^{\circ}$ 07, de 30 de abril de 2015a. Diário Oficial, Brasília, 2015a. p.1-50. Disponível em: <http://www.icmbio.gov.br/cepsul/images/stories/legis lacao/Instrucao_normativa/2015/in_ibama_07_2015_i nstitui_categorias_uso_manejo_fauna_silvestre_cative iro.pdf>. Acessado em: 28 dez. 2016.

BRASIL. Ministério do Desenvolvimento Indústria e Comércio Exterior. Sistema de Análise das Informações de Comércio Exterior. 2015b. Disponível em: <http://aliceweb.mdic.gov.br//consulta$\mathrm{ncm} /$ consultar>. Acessado em: 10 mar. 2016

CHARRUAU, P.; PÉREZ-FLORES, J.; PÉREZJUÁREZ, J.G. et al. Oral and cloacal microflora of wild crocodiles Crocodylus acutus and C. moreletii in the Mexican Caribbean. Dis. Aquat. Org., v.98, p.2739, 2012.

CHIACCHIO, R.G.D.; PENIDO JUNIOR, G.N.; SOUZA, C.A.I. et al. Enterobacterial colonization in captive red-eared sliders (Trachemys scripta elegans). J. Zoo Wild. Med., v.45, p.919-921, 2014.

COSTA, H.C.; BÉRNILS, R.S. Répteis brasileiros: lista de espécies. Herpetol. Bras., v.3, p.75, 2014. Disponível em: <http://www.sbherpetologia.org.br/images/LISTAS/20 14.03-07-MudancasTaxonomicas.pdf $>$. Acessado em: 5 mar. 2015 .

FERGUSON, M.W.J. Extrinsic microbial degradation of the alligator eggshell. Science, v.214, p.1135-1137, 1981.

FERNÁNDEZ, M.S.; SIMONCINI, M.S.; DYKE, G. Irregularly calcified eggs and eggshells of Caiman latirostris (Alligatoridae: Crocodylia). Naturwissens, v.100, p.451-457, 2013.

FERREIRA JUNIOR, R.S.; SIQUEIRA, A.K.; CAMPAGNER, M.V. et al. Comparison of wildlife and captivity rattlesnakes (Crotalus durissus terrificus) microbiota. Pesqui. Vet. Bras., v.29, p.999$1003,2009$. 
FUNKHOUSER, L.J.; BORDENSTEIN, S.R. Mom knows best: the universality of maternal microbial transmission. Plos Biol., v.11, n.8, 2013.

GAIRHE, K.P. An investigation on the causes of mortality in captive gharial hatchlings at the Chitwan National Park, Nepal. 2007. 73f. Dissertação (Mestrado em Ciência Veterinária) - Institute of Agriculture and Animal Science, Tribhuvan University, Rampur, Chitwan.

HUCHZERMEYER, F.W. Crocodiles: biology, husbandry and diseases. [Onderstepoort]: CABI Publishing, 2003. p.1-56,139-156.

HUCHZERMEYER, F.W.; HENTON, M.; RILEY, J. et al. Aerobic intestinal flora of African dwarf crocodiles (Osteolaemus tetraspis) from the Congo Republic. Onderstepoot J. Vet. Res., v.67, p.201-204, 2000

JOHNSTON, M.A.; PORTER, D.E.; SCOTT, G.I. et al. Isolation of faecal coliform bacteria from the American alligator (Alligator mississippiensis). J. Appl. Microbiol., v.108, p.965-973, 2010.

LOVELY, C.J.; LESLIE, A.J. Normal intestinal flora of wild Nile crocodiles (Crocodylus niloticus) in the Okavango Delta, Botswana. S. Afr. Vet. Assoc., v.79, p.67-70, 2008 .

NOVAK, S.S.; SEIGEL, R.A. Gram-negative septicemia in American alligators (Alligator mississippiensis). J. Wildl. Dis., v.22, p.484-487, 1986.

OLIVEIRA, M.G.X.; PRESSINOTTI, L.N.; CARVALHO, G.S. et al. Zoonotic species of Arcobacter isolated from alligators (Caiman yacare) grown for consumption. In: CONGRESSO BRASILEIRO DE MICROBIOLOGIA, 28., 2015, Florianópolis. Anais... S Florianópolis: SBM, 2015. v.28. p.1482-1483. (Resumo).

PARÉ, J.A.; SIGLER, L.; ROSENTHAL, K.L. et al. Microbiology: fungal and bacterial diseases of reptiles. In: MADER, D.R. Reptile medicine and surgery. 2.ed. Saint Louis: W.B. Saunders, 2006. cap.16, p.217-238.

PEUKER, S.K.J.; DAVIS, B.M.; BARNEVELD, R.J. Crocodile farming research: hatching to harvest. [Barton]: Rural Industries Research and Development Corporation. 2005. 111p. Available in: $<$ https://rirdc.infoservices.com.au/downloads/05152.pdf $>$. Accessed in: 20 set. 2016.

QUINN, P.J.; MARKEY, B.K.; CARTER, M.E. et al. Veterinary microbiology and microbial disease. Oxford: Wiley-Blackwell, 2001. 544p.
RAUF, M.M. Hatchability of Nile crocodile (Crocodylus niloticus) eggs: association with bacteria and fungi in incubation boxes and in eggs that failed to hatch. $2015.278 \mathrm{f}$. Dissertation (Master in Veterinary Sciences) - Faculty of Veterinary Medicine, University of Pretoria. South África.

SCHOEB, T.; HEATON-JONES, T.G.; CLEMMONS, R.M. et al. Clinical and necropsy findings associated with increased mortality among American alligators of Lake Griffin, Florida. J. Wild. Dis., v.38, p.320-337, 2002.

SILVA, J.S.A.; MOTA, R.A.; PINHEIRO JÚNIOR, J.W. et al. Aerobic bacterial microflora of broadsnouted caiman (Caiman latirostris) oral cavity and cloaca, originating from Parque Zoológico Arruda Câmara, Paraíba Brazil. Braz. J. Microbiol., v.40, p.194-198, 2009.

SINGH, B.R.; SINGH, V.; EBIBENI, N. et al. Maternal transfer of bacteria to eggs of common house gecko (Hemidactylus frenatus). J. Microbiol. Res., v.4, p.78-85, 2014

SOUMET, C.; ERMEL, G.; FACH, P. et al. Evaluation of different DNA extraction procedures for the detection of Salmonella from chicken products by polymerase chain reaction. Lett. Appl. Microbiol., v.19, p.294-298, 1994.

SUH, K.D.; SONG, C.J. Prevalence of Lawsonia intracellularis, Brachyspira hyodysenteriae and Salmonella in swine herds. J. Vet. Sci., v.6, p.289-293, 2005.

WHITE, J.; RICHARD, M.; MASSOT, M. et al. Cloacal bacterial diversity increases with multiple mates: evidence of sexual transmission in female common lizards. PLoS One, v.6, n.7, 2011.

WILLIAMS, P.A.; MITCHELL, W.; WILSON, G.R. et al. Bacteria in the gular and paracloacal glands of the American alligator (Alligator mississippiensis; Reptilia, Crocodilia). Lett. Appl. Microbiol., v.10, p.73-76, 1990

YOON-SEOK, R.; PARK, H.; CHO, H.U. Aeromonas hydrophila-associated septicemia in captive crocodiles (Crocodylus johnstoni and Crocodylus porosus). J. Zoo Wild. Med., v.42, p.738-742, 2011.

ZANCOLLI, G.; MAHSBERG, D.; SICKEL, W Reptiles as reservoirs of bacterial infections: real threat or methodological bias? Microbiol. Ecol., v.70, p.579-584, 2015. 